\title{
Impediments to the Actualization of Legislation on Local Brew in Kenya: a Study within the Kenya-Uganda Border Community, Busia County
}

\author{
Dr. Evans M. Oruta \\ Lecturer: Department of Criminology and Social Work, Masinde Muliro University of Science and Technology, \\ P.O Box 190- 50100, KAKAMEGA, KENYA \\ Email: eoruta@mmust.ac.ke \\ Levis Omusugu Amuya \\ Institute of Criminology, Forensics and Security Studies, Dedan Kimathi University of Technology, \\ P.O Box 22992 - 00100, NAIROBI, KENYA \\ Email: lokamuya@gmail.com
}

\section{Abstract}

Despite the aggressive efforts by the legislators and the moralists to demonize local brew in Kenya, Chang'aa and busaa have withstood all the suppression and they remain the most preferred alcoholic drinks for rural and lower class citizens. This study made an inquiry into the challenges facing the implementation of local brew policies, with specific focus on the Alcoholic Drinks Control Act, 2010 and the County Alcoholic Drinks Control Act which is currently being adopted by the counties across Kenya. The study area was unique in the sense that it strategically links Kenya and Uganda and there are deep intricacies in relation to cross border relations. No such study has been conducted in a local community along the Kenya-Uganda border with a long history of local brewing in the western parts of Kenya. The study data was collected from 60 local brewers using questionnaires. Personal interviews were used in gathering data from key informants that included 10 police officers and 10 national administrators. The study found major pitfalls both in the design and implementation of the policies on local brew. The study revealed that the major policy implementation challenges are related to influence from traditions, skewed implementation and coordination measures, inadequate implementation resources, poor conduct of the implementing officers, poor court practices and increased smuggling of substandard brew from Uganda. The police are some of the beneficiaries of local brew illegalization efforts since they fleece money from the gullible local brewers. The study recommended that local brew should be legalized and standardized because the current prohibition efforts only benefit Ugandan economy and promote the growth of the black market at the Kenya-Uganda border. There is a need for more investment on the socioeconomic aspects of life that more often lure people to local brewing. The study findings challenge the government to consider meditating upon the realities on the ground before prohibiting local brew.

Keywords: Actualization, Legislation, Policy, Public Participation

DOI: $10.7176 / \mathrm{JLPG} / 109-08$

Publication date:May $31^{\text {st }} 2021$

\section{INTRODUCTION}

The problem of excessive consumption of local brew in Kenya has been historical, and it continues to haunt the country since it is considered as a source of many social problems. Even though the country has been using aggressive and vigorous legal interventions to avert the situation, there has been no significant success. The interventions to curb local brewing have only been counterproductive as local brew producers and drinkers continue to fill the prisons, remands, the courts, and even rehabilitation centers. The war on local brew seems to benefit the wealthy with the ability and capacity to run bars where commercial alcohol is sold and local brew is smuggled, including sub-standard alcohol from Uganda. Developing countries have been expanding their focus on encouraging the controlled consumption of the commercially produced alcohol beverages while local brew have been demonized. African countries such as Kenya have been busy fighting for utter eradication of their local brew yet the poor and local civilians are still insisting on using the local brew (Willis, 2006; Clausen et al., 2009).

The war against local brew is viewed as the war against the poor consumers and producers who cannot afford the commercial beer in pubs and nightclubs. In countries such as Uganda, standards have been developed by the government on the brewing and packaging of Waragi (Odejide \& Ibadan, 2006). Conversely, Chang'aa and Busaa in Kenya have still not been properly regulated but the government just insists on their prohibition, a measure that seeks to control peoples' appetites. That explains why the trends on the consumption of local brew 
don't inspire (Gathura \& Fortunate, 2012). The reports that local brewers have been using unorthodox methods in producing their brew have done little to scare the consumers who seem to be impassioned to continue celebrating the local brew (Chesang, 2013; Gayle, 2014).

It is quite startling how the Alcoholic Drinks Control Act of 2010 that reduces the drinking hours around the country is easily and vastly broken (Gathigah, 2015). Most of the people who fear being arrested in the pubs during the day have resorted to drinking local brew sold in the backstreets and villages. Soon after its implementation, some bar attendants developed survival mechanisms and secret dealings to serve their faithful customers.

Most of the alcohol sold in such arrangement is collected from the villages and sold for commercial purposes. The bar operators simply induce the local police and national administrators to allow patrons to freely drink to their measure (Gathigah, 2015). The excessive and illicit consumption of alcohol are symptoms of major socialeconomic challenges in Kenya that policies on alcohol fail to address (GoK, 2010). A 2012 national survey by NACADA found that traditional liquor is the most easily accessible especially among the poor (NACADA, 2012). There has been increased demand for local brew after the government tightened the legislation on the use of commercial beers including increased pricing.

\subsection{Statement of the problem.}

Enacting laws on the prohibition of local brew is one thing; enforcing them is another. Since the 1980s, legislation efforts have intensified with the government establishing statutes to govern the manufacture, sale, and consumption of alcohol and other local brew. These include the Chang'aa Prohibition Act 1980, the Liquor Licensing Act 1986, the Traditional Liquor Licensing Act 1991, and Alcoholic Drinks Control Act, 2010. Besides these legislations, the government established the National Agency for the Campaign Against Drug Abuse (NACADA) in March 2001, "to coordinate the activities of individuals and organizations in the campaign against the excessive use of local and commercial brew". However, the enactment of the alcohol laws has had an impact of increasing the consumption of local brew in Kenya (GoK, 2010). Kenyans are drinking more locally produced brew today than ever before with the trend expected to continue mounting, despite the introduction of tough control and regulations. This is an indication that implementation of the alcohol policies have been slow, and faces many legal bottlenecks from the major players in the alcohol industry (Mwathane, 2013). The majority of the licensing and enforcement officials lack sufficient equipment for their work and they do not know some fundamental aspects of local brewing. The manner in which the laws are being implemented has even been exposing police officers and national administrators to numerous risks. Recently, villagers attacked and set ablaze two administration police officers who had gone to raid a chang'aa den in a village in Voi after being suspected to be thugs terrorizing the residents (Muraya, 2017). Such cases are just a tip of the iceberg on the unconventional manner in which raids are being conducted by the police. National administrators have attracted numerous enemies from their own communities out of the war on illicit brew, a war that the brewers feel is selective and ill motivated. The brewers have even gone to an extent of dropping threatening leaflets to the homes of the chiefs who give the police leads on the illicit brew dens (Macharia, 2016). The implementation has been taken to imply that the government moved too fast while enacting the alcohol law. It was reacting to the cries of families in central Kenya as well as increased media stories demonizing the use of local brew. As a result, the legislation was enacted without engaging the public and other stakeholders thus leading to resistance during its implementation (Mkwesha, 2014). Previous studies on alcohol have focused on the commercial beverages, as well as the impacts of alcohol on various sections of the population such as the youth, students and town dwellers (Masaba, 2017; Masinde, 2014; Otieno, 2015). The purpose of this study was therefore to identify the main challenges that make the realization of legislation on local brew an illusion in Kenya, with Teso South Sub-County, a place in the Kenya-Uganda border that is long considered as a hub of local beer, as a study area.

\subsection{Objective of the study}

The main objective of the study was to investigate the challenges facing the implementation legislation on local brew in Teso South Sub-County.

\subsection{Theoretical framework for the study.}

The study is based on the Contextual Interaction Theory (CIT) of policy implementation that has been applied in several studies on policy implementation (Bressers \& O'Toole, 2005). The basic assumption of this theory is that the course and outcome of the policy process heavily depends not only on inputs but more crucially on the characteristics of the actors involved, their motivations, the information they rely on and the power dynamics 
(Bressers \& O'Toole, 2005). Motivation is abstracted in terms of the level of significance actors place on a particular a legislation and the degree to which legislation contributes to their goals and objectives. Thus, the theory underscores the engagement of the public in the formulation of the policy.

It is also viewed in terms of serious commitment of resources to the policy implementation process. Information, according to this theory, includes general knowledge aspects such as policy awareness for relevant actors and the citizens, understanding of policy requirements and benefits, technical knowledge of the matter at hand and patterns of communication between actors about the policy and how to comply. According to this theory, for policy to be successful, there must be a serious commitment of recourses, policy actors equipped with relevant information concerning the policy as well as the political support of the policy implementation process (Bressers $\&$ O'Toole, 2005). The assumptions of the Contextual Interaction Theory can be used in understanding the alcohol regulation policies and the upheavals to their actualization.

\section{LITERATURE REVIEW}

The history regarding the legality of homebrew has been a complicated one. The Traditional Liquor Licensing Act of 1971 and the Chang'aa Prohibition Act of 1980 that forbade any efforts to produce, sell, supply, consume or possess chang'aa were questioned due to their defectiveness that was mostly felt in the 1990's after they failed in addressing the shortcomings in the consumption of alcohols and spirits (GoK, 2010). The Alcoholic Drinks Control Act was enacted in 2010 and it provided guidelines for dealing with the adulteration of, the education in relation to, and the enforcement of the safe consumption of such products (Teaka, 2015).

There have been some recent cases of hundreds of liters of chang'aa parked in polythene bags being nabbed by police officers while it is being transported to towns such as Eldoret and Kitale. Cases like this are on the rise and it has promoted the adulteration of chang'aa collected from western Kenya since the demand is high in towns (Mugo, 2016). As a result, the police and other implementing officers in Kenya have been leading disjointed campaigns in implementing legislations on local brew. Previous arrests made by police officers have been marked by the mishandling of producers and sellers of local brew and blatant violation of human rights leading to serious consequences (Onyango, 2017). The emergent risks and incidents related to the enforcement of laws on locals brews point out the existing implementation challenges of these laws because the lives of both the public and the police are at risk especially for communities at the Kenya-Uganda border.

\subsection{Overview of local brewing in Teso community.}

The use of local brew has historical roots in Teso community. Reaching back in time, local brew such as busaa was enjoyed socially by mature adults with position and proper standing in society. The brew was only consumed after people fed well. During naming ceremonies, the child was given a sip of busaa in what is known as a Adere and it was presumed that when the child cries after being given a sip of the brew, it had snubbed the name. Local brew was also used in funeral ceremonies, buying of land and during the consecration of twins. People commonly drunk busaa during community rotational farming and before planting millet every season is what famously known as Ekitai. The regulation of brew consumption was natural since the traditional social structures of the time ensured that the social norms entailed in the use of local brew were observed. Drinking was only done during the evening hours victims of irresponsible drinking habits were few.

Drinkers who behaved in a discordant manner were fined in terms of animals such as sheep and cows, which were mostly slaughtered at the scene to reconcile the offender with the community. The historical significance of local brew in the Teso community, therefore, means that outlawing them is an uphill task that requires a wellreasoned out public policy. In modern times, regulation has become necessary since people drink without eating while others treat the drinking of local brew as a hobby because it is cheap compared to commercial alcohol. Excessive drinking has cost the Teso community numerous families, although, unlike most parts of Kenya, there are no statistics indicating instances when local brew has led to the death of people unless a person is intentionally poisoned. These and other twists in Teso and other parts of the Kenya have prompted the rushed regulation or illegalization of production and consumption of local brew (Mwathane, 2013). However, the policies enacted by the national and county governments are still far from realizing their objectives. In most parts of Kenya, the consumption of busaa is still very popular among social and religious ceremonies, such as weddings and funerals (News24.com, 2015). This study sought to illuminate the reasons for the failure of local brew prohibition efforts. 


\subsection{Policy implementation challenges.}

Issues of policy failure have always attracted the attention of social scientists though policy makers have only been focused to the proposition of policies as a prerequisite to their success (Weaver, 2010). For a policy maker, a good policy can always be implemented effectively (Hill \& Hupe, 2014; Birkland, 2014). Policy implementation difficulties, failures or loopholes usually emerge when the policy is blindly imposed from the center with little regard and consideration of the local level. As policies failed to achieve the desired policy expectations, processes of actualizing the designed policy into action attracted much attention leading to the emergence of two major approaches to the study of policy implementation (Barrett, 2004; Pulz \& Oliver, 2007). The top-down approached views implementation efforts in a hierarchical system while the bottom up approach views the policy implementation as a daily mission that needs continued formation of strategies by the executives and bureaucrats (Barrett, 2004). The failure of a policy to attain its desired objective can result from bad execution of a policy or the policy being inappropriate in the first place. Moreover, policy implementation failure has also been understood based on the defectiveness of the policy itself in the sense that it is predicated on insufficient information or poor reasoning by the policy makers. More often, whatever transpires during the policy implementation stage has the potential of influencing the outcome of the actual policy in a way that might not have been foreseen. The likelihood of successful results as desired by the policy maker will be increased if the potential implementation problems are explored during the policy design stage (Birkland, 2014). At times, the challenges associated with the implementation of policy emerge as a result of an inability to examine conduct a comprehensive analysis of the policy strengths and weaknesses (Weaver, 2010).

Analysis of the policy strengths and weaknesses serves the purpose of pointing out whether policy priorities can yield the expected outcomes. Moreover, such an analysis interrogates whether policies are consistent with the priorities and objectives of the country while considering the institutional settings and arrangements (Hill \& Hupe, 2014). Kielstra (2010) identified crucial factors in policy implementation process to include; clear policy communication, implementation resources, disposition or attitude as well as bureaucratic structures and mechanisms that would enable all the other four aforementioned factors to operate simultaneously and link up with each other (Deborah, 2008).

The absence of policy clarity and consistency of policy goals also large present barriers to policy implementation. In many occasions, the policy objectives are often complex and broadly based. It has very tough provisions that make it difficult to implement. Due to their being vague, most policies and their goals are casual and they are not detailed well enough to identify the paramount focus areas and existing inconsistencies (Kielstra, 2010). In addition, Spratt (2009) found that the existence of a yawning gap between policy intentions and the results constitute a major challenge to policy implementation in most developing countries (Spratt, 2009). Scenarios like this only provoke memories of 'good' policy ideas that never worked and the ultimate persons to be blamed are the formulators of the policy as well as the policy administration teams.

\subsection{Public Participation in the Policy Making Process.}

Public participation is a political principle or practice, and may also be recognized as a right. According to Abelson \& Gauvin (2006), public participation is part of "people centered" principles, which have emerged in Western culture over the last thirty years, and has had some bearings of education, business, public policy and international relief and development programs (Pulzl \& Oliver, 2007). Public participation is advanced as part of a "people first" paradigm shift (Bryson et al., 2013). Public participation is used as a tool in carrying out and ensuring the success of fundamental initiatives such as planning, organizing or funding of activities (Michels \& De Graaf, 2010). In some jurisdictions, the right to public participation is enshrined by law. Democratic societies have incorporated public participation rights into their laws for centuries (Abelson \& Gauvin, 2006). The state has a preliminary and fundamental duty of making sure that citizens understand the law for proper implementation purposes. The famous maxim "Ignorance of the law is no excuse" holds that the citizens have a duty of understanding the law and its provisions (Ikelegbe, 2006). Thus, the government makes steps that include printing books of law and avail them for public readership (Bryson et al., 2013). In the alcohol regulation initiative, there seems to be less public participation in the whole process of developing policies. For instance, the Alcoholic Drinks Control Act of 2010 that was enacted to limit the sale of alcohol, control bar operation times and prescribe penalties for the violators temporarily halted after a bar owners association from Central Kenya lodged a complaint in court to bar its implementation (Mureithi, 2010). Moreover, most of the citizens were acrimonious about the law, an implication that the public and stakeholder views were not sourced for at the time the policy was being developed. 
This ended up causing a serious impediment to the success of the policy. County Alcoholic Drinks Control Act, 2013 model law seeks to expedite public involvement in all matters linked to the control of alcoholic drinks control as required by the County Governments Act 2012 and other relevant written laws (The Republic of Kenya, 2013). However, this purpose has not been fully realized as manifested in the current state of affairs where by citizens are not properly furnished with information relating to alcohol legislation. People would only accept and actualize the policy if they are engaged in the decision-making processes. Stakeholder engagement in making decisions is the central feature of change management endeavors. Where stakeholders are not consulted, the policy implementation course will always be hampered irrespective of the viability of the idea.

According to Hill \& Hupe (2014), only designing good policies is insufficient for their effectiveness. There is a need for countries move beyond the proper designing of policies if they are to be successfully implemented. There is a need for the policy maker to build a consensus with all the stakeholder in order to effect successful implementation. Bringing all the stakeholders together ensures that they all work to achieve a common purpose and they would not be colliding with one another. The process of change is usually hampered by numerous upheavals and thus, all the players to be convinced that their engagement will be beneficial to the majority.

\subsection{The Impact of Resource Availability on Policy Implementation.}

For a policy to be implemented properly, there is a need for the clear definition of the required resources and who might provide them. Implementing the policies on the regulation of local brew in rural villages is quite challenging and complex. This is because the issues associated with the problem of drinking local brew affects community-level health and safety as well as people's habits. The undertaking is even more challenging due to the fact that use of local brew is socially acceptable in some families and the community in general. Despite these challenges, most governments in the world over have formulated alcohol regulation policies in an attempt to curb the increased use of local and commercial brew. However, resources have been cited as one of the reasons as to why alcohol regulation policy is not creating impact in communities. Generally, the absence of adequate resources will result in implementation problems thus contributing to the ineffectiveness of any public policy. Nelson et al., (2010) observes that the resources channeled to an agency or institution for implementation purposes need to integrate with its processes. Such resources should not cause extensive competition, interference, and conflicts.

There must be leaders who have the requisite skills, are supportive of the objectives, and have the necessary resources. Agencies may not be supportive of the policy objectives or may not place them high on their list of priorities thus denying those policies the resources that are required for them to be wholly implemented. Lack of direct and indirect resources to support the change and policy implementation is a great obstacle to the success of the policies (Mkwesha, 2014). Resources include both human and material such as legal resources, well facilitated police officers and enough funding to promote civic education in the alcohol control policy, relevant and adequate information on implementation process, the authority to ensure that policies are carried out as they are intended. When the country is devoid of sufficient resources, the implementation and enforcement of laws will be stalled.

Also, inadequacy in resource capacity hampers service provision the development of reasonable regulations will also be affected. According to Toomey et al., (2011), lack of money or other resources to adequately conduct alcohol enforcement is a barrier to its effective enforcement. Funds are needed for implementation, but the ones available are usually not adequate, which makes reaching policy objectives difficult (Wall et al., 2012). Moreover, Spratt (2009) notes that resources can also be in terms of data, books, and newsletters. The need for data resources is among the challenges to creating more rational crucial alcohol control programs. Thus, resources form a basic element to aid in the successful realization of the alcohol control policies that have been enacted by the government.

\section{METHODOLOGY}

A descriptive study design was used in carrying out this research. Quantitative data was collected through a survey of 60 producers and sellers of the local brew joints sampled randomly. The brewers were sampled from specific villages where local clubs were rampant. Personal interviews were used in gathering data from key informants that included 10 police officers and 10 national administrators sampled purposively because of their intimate knowledge of policy implementation challenges. Secondary data was collected from the literature reviewed to complement the primary data. The data collected was coded and analyzed using the Statistical Package for Social Sciences (SPSS) version 22.0 for windows. Findings were presented using tables and charts. Qualitative data gathered from key informants were transcribed and organized into themes as they emerged during the study and reported in the form of direct quotations and in-depth analyses. Thereafter, similar 
responses were tallied and inferences, conclusions, and recommendations drawn. These procedures enabled the researcher to describe the broad classification of variables under the study and how they relate to the implementation of legislation on local brew.

\section{FINDINGS}

\subsection{Demographic information}

\subsubsection{Marital status of local brewers}

\section{Marital Status of producers and sellers of local brew in Teso South}

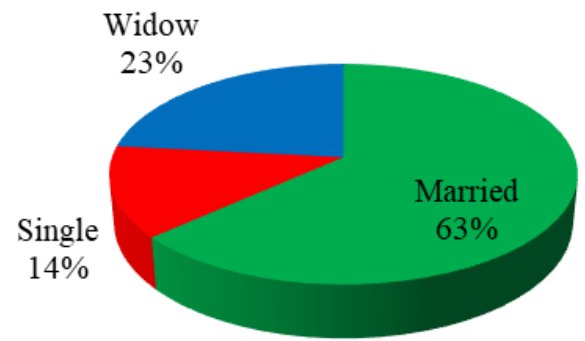

Fig 1. Marital status of local brew producers and sellers.

From Fig 1 above, $23 \%$ of local brewers and sellers are widowed, $13 \%$ are single parents while $64 \%$ are married. Findings show that most of married people in Teso south are more inclined to engage in the local brew business to provide for their families. The married respondents languish in abject poverty and the single parents and widows alike have no reliable sources of income.

\subsubsection{Gender of local brewers and sellers.}

\section{Gender of local brewers and sellers}

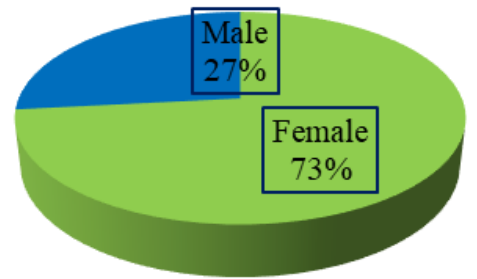

Fig 2. Gender of local brewers and sellers in Teso south sub-county.

From Fig 2 above, $73 \%$ of local brewers and producers are female while $27 \%$ are male. The majority of the female producers and sellers of local brew are widows and single mothers striving to raise their children. 


\subsubsection{Level of education of producers and sellers of local brew.}

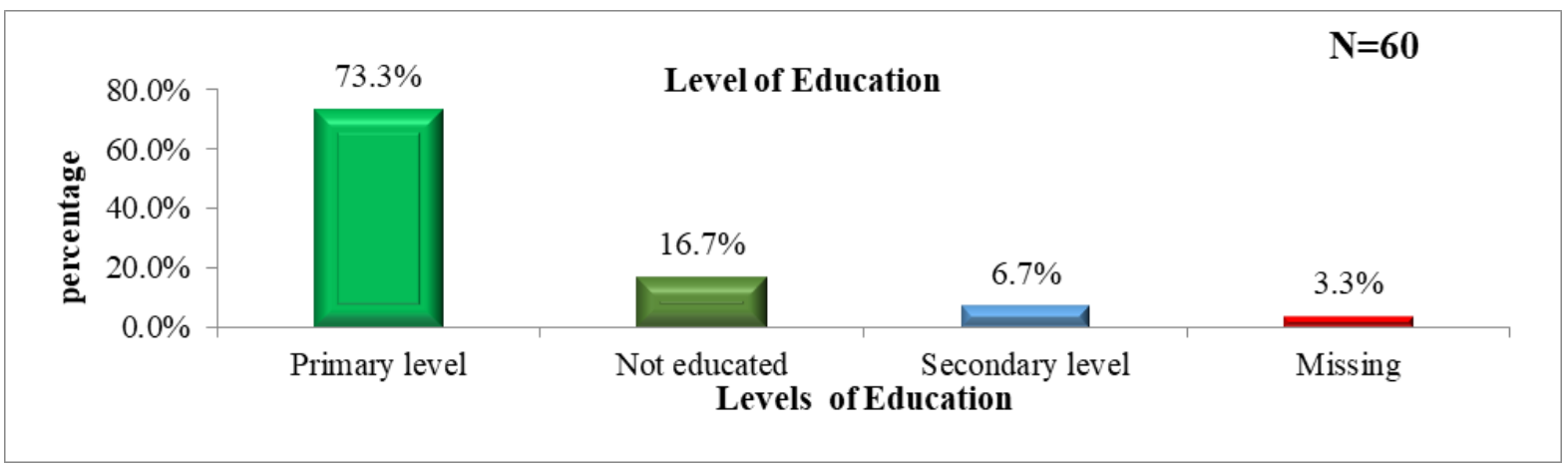

Fig 3. Level of education of producers and sellers of local brew in Teso south sub-county.

Fig 3 above shows that $73.3 \%$ of local brewers attained primary education while $6.7 \%$ attained secondary education. $16.7 \%$ have not received any education. These findings reveal that local brewing and sale is common among the poorly educated citizens who have no opportunities for other income generating activities since they have no employable skills. Masaba (2017) found that illiteracy is a major factor that contributes to alcoholism.

\subsubsection{Common type of brew produced and sold in Teso South sub-county.}

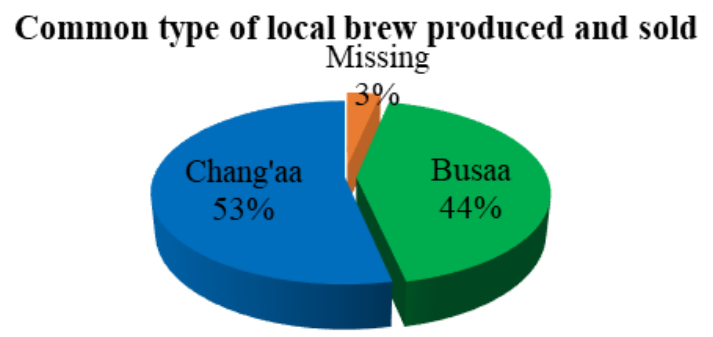

Fig 4. Type of brew produced and sold.

Chang'aa is the most common type of local brew in the region since it is produced and sold by $53 \%$ of the producers and sellers. $44 \%$ of the respondents produce and sell Busaa. Consumers applaud it to be cheap and the profits are doubled for the sellers. On the other hand, busaa is produced due to a perception that it is not "illicit" as the law insists because its raw materials are common foods used by people such as maize, sorghum, and millet. Busaa drinking has been a culture that has been translated from generation to generation. Masaba (2017) found that availability of alcohol is one of the major factors leading to alcoholism. 


\subsubsection{Occupation of local brewers and sellers in Teso South sub-county.}

\section{Occupation of local brewers and sellers}

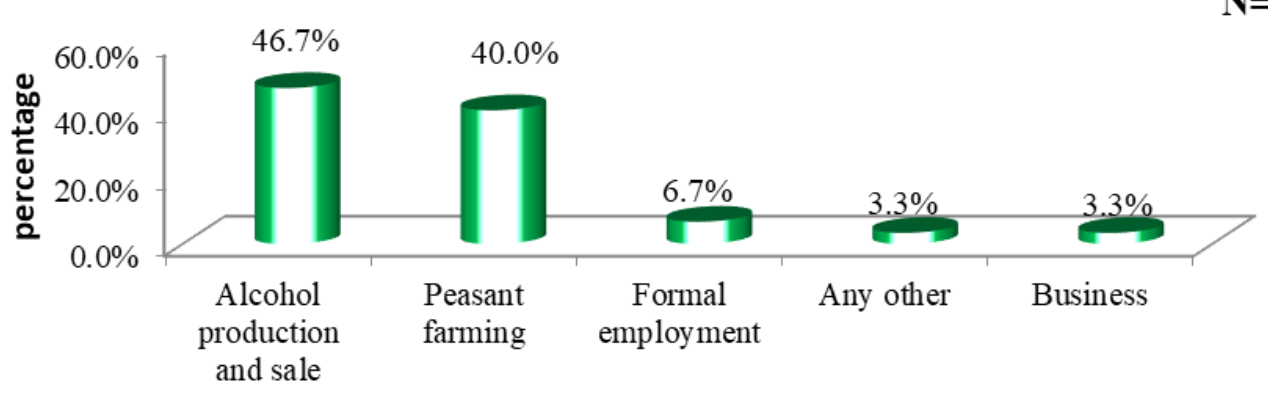

\section{Fig 5. Occupation of local brewers and sellers in Teso South Sub-County}

Fig 5 above shows that $46.7 \%$ of the local brew producers and sellers rely solely on alcohol production and sale, $40 \%$ are peasant farmers, while $3.3 \%$ are engaged with small scale business. Only $6.7 \%$ have formal employment. 3.3\% are involved in other activities such as sand harvesting as a way of earning income. These findings conform to those of Masaba (2017) who established that $68 \%$ of the alcohol consumers and sellers in Busia were unemployed. The implication is that what needs to be addressed is the economic stresses that the local residents go through.

\subsubsection{Reason for production and sale of local brew in Teso south sub-county.}

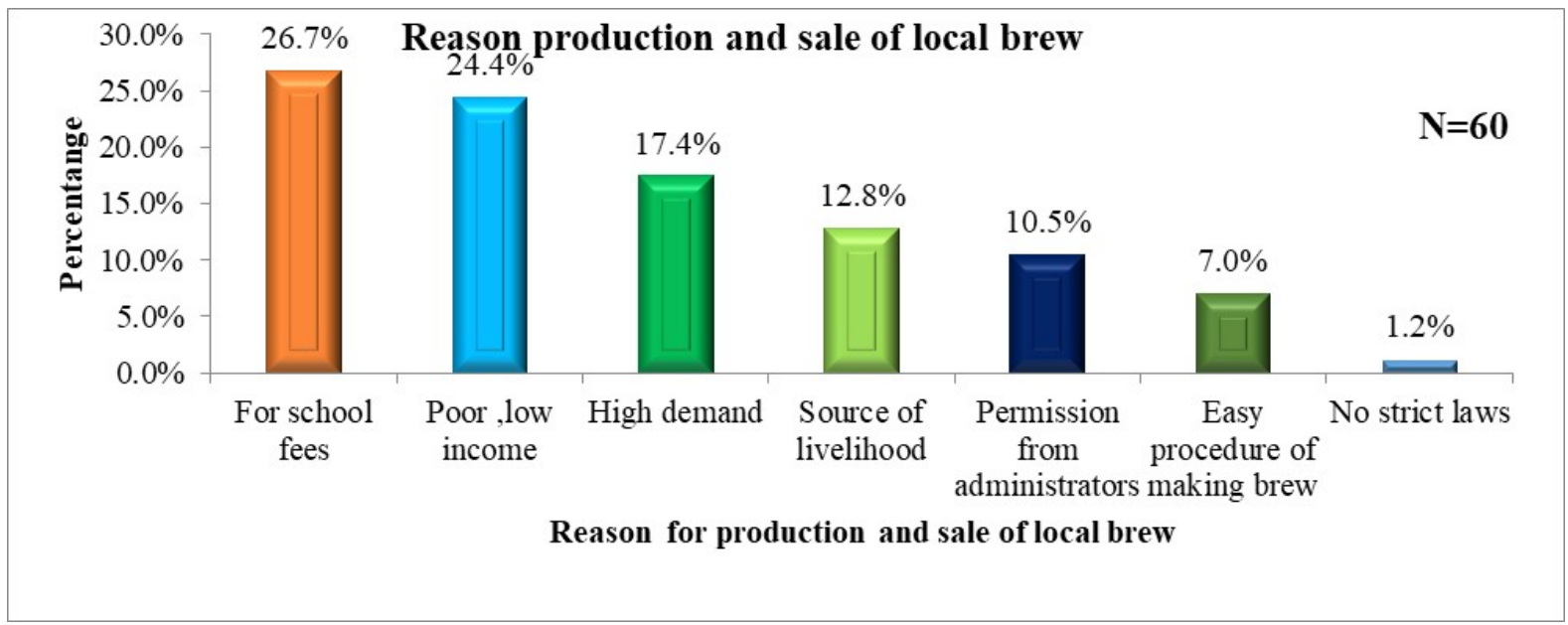

Fig 6: Reason for production and sale of local brew in Teso South sub-County.

Fig 6 shows that $26.7 \%$ produce and sell local brew to raise school fees for their children, $17.4 \%$ produce and sell the local brew because they are in high demand in the region. The majority of the respondents produce the brew on a weekly basis to meet the existing demand both locally and in other major towns such as Eldoret and Nairobi. Also, the study shows that $24.4 \%$ produce and sell because they have poor or low income while $12.8 \%$ depend on local brew as their main source of source of livelihood. Local brewing and sale are considered as an activity that boosts subsistence farming in the region. In some instances, it emerged that even disabled people produce and sell local brew due to poverty and economic upheavals. Findings also show that $7 \%$ of the local brewers and sellers indulge in the practice because it is easy to make local brew while $1.2 \%$ do so because the existing laws are friendly. $10.5 \%$ of the respondents indicated that some of the chiefs are more understanding of the local economic difficulties and allow people to make local brew. Respondents highlighted those lenient administrators notify the producers in case a raid is planned and sometimes chiefs advise people to produce and sell secretly. 


\subsubsection{Arrest and prosecution of local brew producers and sellers in Teso South Sub-County.}

Local brew producers and sellers were asked whether they have been arrested and prosecuted, arrested but not prosecuted, reasserted, or whether they have never been arrested as a result of local brew production and sale. Findings are shown in Fig 9 below.

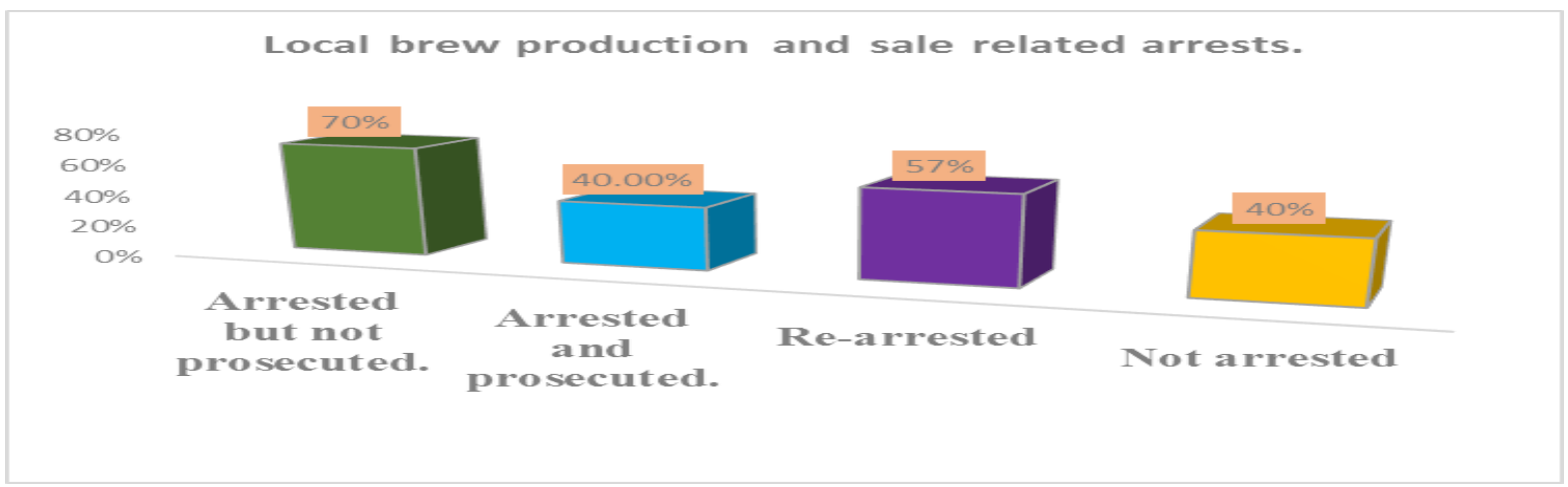

Fig 9: Local brew production and sale related arrests.

Findings show that $40 \%$ of the respondents have been arrested and arraigned in court. The respondents arrested and prosecuted by charged between Ksh. 5000 and Ksh. 50,000. Those charged Ksh. 50, 000 were mostly accused of transporting chang'aa to major towns such as Nairobi and Eldoret. $57 \%$ of the respondents have been re-arrested due to production and sale of local brew. This means that despite the policy interventions, the rates of prosecution and sale of illicit is still high. Some of those re-arrested indicated that they were not arraigned in court having bribed the police at the station level. Bribes were between Ksh. 1000 and Ksh. 5000 depending on how chronically the producer and seller had been arrested. The rate of those arrested but not prosecuted stands at $40 \%$. This means that the police stand out as the beneficiaries of alcohol control policies. Findings show that police officers have no confidence with the manner in which the courts execute cases involving local brew. Thus, they resort to releasing the brewers and sellers upon the collection of some bribes from them.

\subsection{Public participation in policy formulation.}

The study sought to establish whether the local citizens were involved in the formulation of the county and national government policies on local brew.

\subsubsection{Local brewers' responses on the awareness of the existence of alcohol related policies.}

\section{Local brewers' awareness of the existence of alcohol policies.}

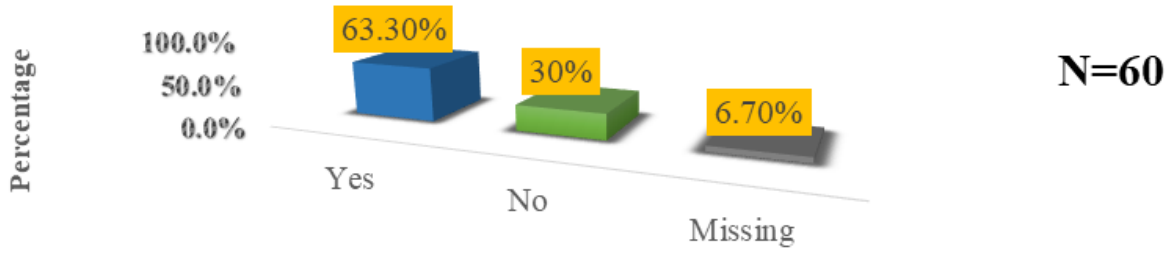

Response

Fig 7: Local brewers' awareness of the existence of alcohol policies.

The Fig 7 above shows that $63.3 \%$ of the local brewers and sellers are aware that there are policies regulating the production and sale of local brew while $30 \%$ indicated a lack of knowledge of the existence of any alcohol related policies. The findings show that some of the citizens from the local community do not have a remote idea of policy intervention in alcohol use. They had not been invited to any public baraza to contribute their ideas to 
the policy development and content. It is very unfortunate that much of public policy assumes society to be a passive object of intervention. According to Miranda (2007), community participation leads to the empowerment of the community. For the purposes of effective policy making, community participation should not just be an exercise when the community is the beneficiary but rather a partner in decision making.

\subsubsection{Local brewers' knowledge of the alcohol policy content and provisions.}

Local brewers' knowledge of the alcohol policy content

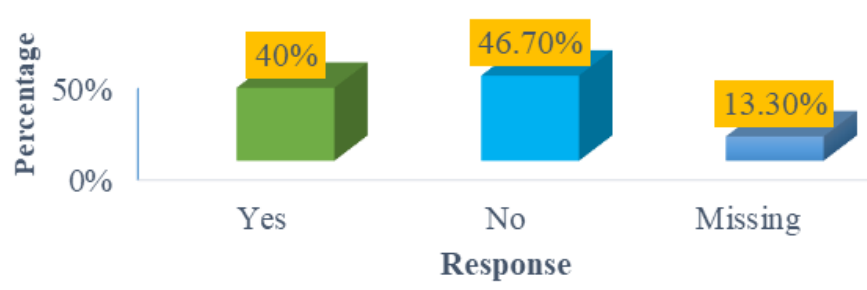

Fig 8: Local brewers' knowledge of the alcohol policy content

Among the respondents who were aware of the existence of the alcohol policy, $40 \%$ had the knowledge of its content while $46.7 \%$ did not know the requisite provisions of the policy. They only indicated that they know that local brew have been outlawed by the government. The respondents indicated that they did not attend a public baraza during the policy formulation stage and most of them are ignorant to read the policy by themselves. During the public baraza organized by the chiefs, the only information that people are being given is that local brew have been outlawed but the details of the policy are hardly provided. Generally, public participation seeks and facilitates the involvement of those potentially affected by or interested in a decision. Public participation may be regarded as a way of empowerment and as a vital part of democratic governance (Michels \& De Graaf, 2010). When citizens are locked out of the consultative discussions that seek to formulate alcohol related policies, their implementation becomes an uphill task.

Despite the alcohol policies having been crafted and implemented, residents continue to indulge in its production, sale, and consumption. According to the study, the reason for this state of affairs was that there are no bars at the interior regions from where people can purchase and drink commercial beers advocated by the government. The only alcohol available is local brew. In the words of a national administrator, "Even where bars are available, the beers and commercial spirits sold are expensive and cannot be afforded by the poor local people." Respondents also reported that most of the residents are idle and have no any other serious activities to engage in. It was also underscored that culture necessitates the use of local brew especially in important cultural events such as the naming of children. Moreover, politicians encourage the production and use of local brew and most of the citizens have no knowledge that the county government is now in charge of alcohol related legislation.

\subsection{Responses from key respondents on the challenges facing the implementation of the alcohol policy}

The study sought to investigate the major challenges facing the implementation of the alcohol policies in Teso south sub-county. The study used 10 police officers and 10 national administrators as key respondents. They were asked to indicate the extent to which they either agree or disagree with the identified challenges. The options ranged from 1 (strongly disagree), 2 (disagree), 3 (not sure), 4 (agree) and 5 (strongly agree). Table 2 below presents the comparative findings of police officers and national administrators in Teso South sub-county.

\section{Table 2. Challenges facing the implementations of the alcohol policy.}

A total of 20 key informants for the study that included police officers and national administrators were asked to indicate their level of agreements with the identified challenges to the implementation of the alcohol policy in the region. Findings are shown from table 2 below. 
Table 2: Challenges facing the implementations of the alcohol policy.

\begin{tabular}{|c|c|c|c|c|}
\hline \multirow[b]{2}{*}{ Implementation Challenges } & \multicolumn{2}{|c|}{ Police officers } & \multicolumn{2}{|c|}{$\begin{array}{l}\text { National } \\
\text { Administrators }\end{array}$} \\
\hline & Mean & $\begin{array}{l}\text { Std. } \\
\text { Deviation }\end{array}$ & Mean & $\begin{array}{l}\text { Std. } \\
\text { Deviation }\end{array}$ \\
\hline Lack of operational agencies to implement the policy. & 4.08 & 0.282 & 2.4 & 1.172 \\
\hline Lack of stakeholder consultation. & 3.77 & 0.587 & 3.52 & 1.311 \\
\hline $\begin{array}{l}\text { Lack genuine of consensus among the policymakers and } \\
\text { stakeholders in the alcohol industry. }\end{array}$ & 3.85 & 0.543 & 3.86 & 1.049 \\
\hline Collusion with the local brewers by local leaders. & 4.08 & 1.017 & 4.14 & 1.26 \\
\hline $\begin{array}{l}\text { Policy implementers are stakeholders in some local brew } \\
\text { dens. }\end{array}$ & 2.31 & 1.011 & 4.24 & 0.759 \\
\hline Lack of political will and negative influence by of politics. & 4.23 & 0.908 & 4.33 & 0.902 \\
\hline No follow-ups to policy implementation results. & 4.23 & 1.07 & 4.24 & 0.692 \\
\hline Poor development of guidelines on policy implementation. & 3.92 & 0.628 & 3.29 & 1.175 \\
\hline Corruption and non-compliance among local implementers. & 3.92 & 0.628 & 4.25 & 0.056 \\
\hline $\begin{array}{l}\text { The alcohol policy is defective and is based on inadequate } \\
\text { information, poor reasoning or unrealistic assumptions. }\end{array}$ & 3.77 & 0.587 & 3.48 & 0.917 \\
\hline Lack of coordination of resources and personnel. & 4 & 0.693 & 4.24 & 1.031 \\
\hline Lack of consistency between policies and county priorities. & 4.07 & 0.427 & 4.24 & 0.759 \\
\hline
\end{tabular}

From Table 2 above, the responses by the police officers and the national administrators are closely related. Respondents agreed that community policing officers, national administrators, and police officers collude in drinking local brew as shown by the standard deviation of 1.017 and 1.26 respectively with the mean of 4 (agree). Respondents also agreed unanimously that there is no political will to implement the policy due to negativity from highly placed political figures as shown by the standard deviation of 0.908 and 0.902 . Similarly, respondents agreed in unison that there is a lapse in the follow-up to policy implementation results and that there is a lack of coordination of resources and personnel to achieve policy goals both having a mean of 4 (agree). The policies are also not consistent with the county's objectives and it does not take into account the institutional settings and arrangements priorities. This means that the county plans and not commensurate with the intended alcohol policy goals. As indicated by a police officer, "counties are money-oriented and they would exploit every opportunity that would give them money".

While the national administrators agreed that there is corruption and non-compliance among the national administrators and police officers were not so sure. From the study, it emerged that some regions of Teso South have many sugarcane crushing plants. In places where sugarcane is produced on large scale, the prices of sugarcane have dropped significantly. Consequently, jaggery and molasses are produced and used in local brewing. There are numerous sugarcane crushing plant owners who purchase sugarcane from farmers. In the words of one of the national administrator, "Jaggery plant owners collude with police officers and those arrested have since been bribing police officers thus promoting the making of chang'aa”.

Police officers showed that there are no operational agencies to implement the alcohol policies as shown by the mean of 4.08 and standard deviation of 0.282 . However, national administrators disagreed as shown by the mean 
of 2.4 and standard deviation of 1.172. Also, police officers disagreed that some of the policy implementers are also stakeholders in some local brew dens as shown by the mean of 2.31 while national administrators admitted that police officers and some local administrators are stakeholders in local brewing dens as shown by the mean of 4.24 and standard deviation of 0.759 . It was cited that the resources and personnel are not well coordinated to implement the alcohol policies in the region. Respondents indicated a lack of dedicated personnel who would ensure effective follow up of the policy gaps and results. In addition, follow-ups are crippled by a lack of adequate financial resources.

\subsubsection{The impact of resource availability on the implementation of the alcohol control policies.}

National administrators and police officers were asked whether there were enough financial and other resources that are used for the implementation of the alcohol policy in Teso South. The findings are indicated below. The respondents agreed that there are no enough financial resources being channeled by the government and other agencies to help in the implementation of the alcohol policies. Corruption is a major roadblock to the effective use of the available financial resources in the sector. The agendas of the policy implementers are not oriented towards holistic implementation of the alcohol policies in the sub-county. According to a senior are chief:

"Police vehicles across the sub county are not enough to deal with all the policing priorities in the area. Police officers demand money to fuel their vehicles before carrying out raids. In extreme circumstances, there are no vehicles at all for proper execution of the raids and taking arrested individuals to the police stations and the courts is a major problem. Financial inadequacies also make it difficult for follow ups to be conducted."

\subsubsection{Availability of enough personnel for implementation of the alcohol control policies.}

During the interviews, police officers and national administrators made a consensus that existing personnel is insufficient.

"The police posts in Teso south are scattered and the provincial administrators find it difficult to access police stations easily in case arrests are made or planned. Some locations and sub-locations with Teso-South SubCounty do not have any police posts or outposts. Thus, conducting raids and arrests in the villages is greatly hampered. Moreover, police officers available are few and they cannot effectively indulge their attention to the implementation of the alcohol policy in the region", a senior police officer explained.

The sub county has a total of 37 police officers against a population of 137,507. The national administrators underscored that the elders and the community policing officers who were once resourceful in tipping the law enforcers on the local brew dens and operations have suffered from threats and intimidation from local politicians colluding with the local brewers. Consequently, these volunteers have distanced themselves from working with the police out of fear for their lives. These community policing officers also lack proper incentives hence their levels of cooperation has declined. Findings from the regions bordering Uganda show that there are no sufficient security officers to help the national administrators from intercepting the ruthless smugglers of contraband alcohol from Uganda. Some of these smugglers have political connections and dealing with them has always been problematic.

\subsubsection{Participation of law enforcers in the drinking of local brew.}

National administrators were asked whether some police officers and local administrators also participate in drinking local brew. They agreed unanimously that some police officers and national administrators participate in the drinking of local brew and some of them are even stakeholders in the local brew dens. The respondents explained that the rate of drinking among police officers and national administrators is alarming and this has created great obstacles in the implementation of the alcohol control policy. Corruption has been precipitated in such an environment since officers who drink local brew are paid some dues and given free alcohol by the local brewers in exchange for information on planned raids. It was particularly noted that some police officers collect some stipends every 15 th and 30th day of every month from each local brewing den. Only those brewers who are resistant to police demands are arrested and frustrated by the police.

A national administrator expressed fears that "the police have a culture of raiding me early in the morning and cause increased fear and suspicion. During such raids, the police storm my bedroom and search the house without a mere consideration of my rights to privacy". Such an environment implies that police officers are some of the greatest beneficiaries of alcohol policies because it gives them leverage and a leeway to fleece money from the public. 
Consequently, implementation of the policy is sabotaged and brew sale and production is encouraged. Moreover, the national administrators underscored that the local brew collected during raids are usually resold to the same local brew by the police thus causing havoc in terms of police action effectiveness in the area. These findings conform to those of Mkwesha (2014) who indicated that corruption of the police force and the National administration is a serious challenge in the implementation of policies. Some respondents indicated that those national administrators who do not drink the local brew suffer from stern backlash and victimization from those who drink. Volunteer officers together with village elders drink due to fear of isolation by the community particularly instigated by the sellers and local brewers given that they live among them. A similar concern was raised by the national administrators who expressed fear of backlash from the community who see them as enemies. There has been sharp disagreement among the drinking and non-drinking law enforcers and the citizens have always sided with the drinking enforcers who are perceived to be understanding. There is a lot of discrimination in terms of who should be arrested. The chronic brewers who maintain friendly terms with the police and local administrators are spared during raids or released before they even reach the police station.

\subsubsection{Alcohol policy responsiveness to the cultural diversities at the Kenya Uganda Border.}

The national administrators were asked whether the local brew policy had been formulated based on the realities of Teso South sub-county. Findings are shown in Table 3 below.

Table 3: Responsiveness of the alcohol policies and cross-border dynamics.

\begin{tabular}{llll} 
Response & Frequency & Percent & Cumulative Percent \\
\hline Alcohol policy is realistic & 2 & 20 & 20 \\
Alcohol policy is not realistic & 8 & 80 & 100 \\
\hline Total & $\mathbf{1 0}$ & $\mathbf{1 0 0 . 0}$ &
\end{tabular}

Respondents indicated that the law was not realistic in its effort to outlaw local brew as shown by $80 \%$. The government also failed to take into consideration the social, political, economic and administrative variables at the policy formulation stage. Respondents indicated that there are various cultural diversities relating to the local brewing, a fundamental aspect that was overlooked by the government when designing the policy. Even though the policies give direction on matters local brew, they fail to address the intricacies of the Teso culture. Busaa was particularly seen as a way of life in the Teso traditions. It is embedded in people's culture and it plays a bigger role in major facets of communal life. According to Bryson et al., (2013), the cultural values of the majority of the community members have an influence in the policy priorities. The state has the obligation to protect and respect community values. Apart from being the savior of cultural practices, the law is entitled to enhance the social, economic and political norms of a given community. Wagenaar, et al (2011) found that alcohol is commonly available in celebrations of various kinds, and community celebrations in a majority of communities in most parts of the United States. Police officers indicated that the people are still cherishing their culture that places local brew at the center. According to Masaba (2017), the family history of alcoholism among the youth aged between 22 to 27 years was the major factor causing alcoholism in Busia town. This finding points to the fact that alcohol drinking has been embedded in the culture of most of the residents of Busia and it plays a central role in the communities. It emerged from the study due to the governmental effort to illegalize local brew, most of the local people at the border cross to Uganda to drink alcohol. A senior chief had the following to say:

"There has been an overflow of sub-standard beers from Uganda into Kenya especially around the Kenyan villages bordering Uganda. The most common Ugandan brew such as Eagle and Chairman have infiltrated the Kenyan market and they are sold in local brew dens since they are considered to be cheaper. Kenyans at the locations bordering Uganda have devised a counter-measure of dealing with the consequences of the Alcohol Drinks Act of 2010."

The administrators from areas around the Kenya-Uganda admitted that people cross to Uganda to take local brew because they fear being arrested when caught drinking in Kenya. The Kenyan alcohol control law requires that bars that sell commercial beer should remain closed until $5 \mathrm{pm}$. As a result of the requirement, Ugandan local brew dens and bars are packed with Kenyans all day. Uganda has legalized chang'aa and busaa and other commercial beers are sold at a cheaper price equivalent to that of the local brew. Consequently, Uganda's economy is one of the greatest beneficiaries of Kenya's effort to outlaw local brew. In Uganda, the official time for selling is supposed to be from noon. However, Andanje (2011) found that due to the increased demand from the Kenyan customers, local is sold from the morning. This study found that some of the Kenyans who drink 
from Uganda have formed groups where they pay Ksh. 60 per day and they drink busaa using straws for the whole day. Business is, therefore, thriving in Uganda since most of the Kenyan drinkers cross to Uganda where there is freedom and the Kenyan bars at the border have been forced to close down. Previous findings show that all the customers, especially the truck drivers along the Malaba-Bungoma highway, have had to consider drinking from Uganda as they wait for clearance at the customs (Andanje, 2011). It is interesting to note that during the 1920s when the United States had prohibited all forms of alcoholic beverages, the majority of the neighboring countries such as Mexico and Canada allowed the use of alcohol. Consequently, alcoholic products from this countries were heavily consumed by visiting Americans and the rate illegal smuggling of alcohol into the United States increased exponentially. In fact, the authorities found it difficult to control the Detroit River at the U.S. border with Canada since most of the alcohol was smuggled through the region. This situation is related to the Kenya Uganda border today.

\section{CONLUSIONS.}

A number of conclusions were made based on the diverse findings of the study;

i. Strict law enactment and criminalization of local brew is insufficient due to weak enforcement. The soft manner in which the courts deal with cases on local brew has made the police reluctant to make arrests.

ii. The recommendation of NACADA to ban local brew production, sale, and distribution as a measure to control its continued use is counterproductive and other legislative interventions have promoted increased smuggling, illicit manufacturing, and counterfeiting in the alcohol industry.

iii. The police at the Kenya Uganda border lack the capacity to intervene in the illicit smuggling of local brew due to the elusive nature of the dealings, increased clandestine and violent black market and organized criminal activities, a situation linked to the geographical terrain of the Kenya-Uganda border.

iv. There is also poor coordination between the police and local administrators, corruption and serious interference from local politicians. At times there is mistrust among the implementers and the public leading to violence from villages during police raids.

v. The alcohol policy does not have the legitimacy to the citizens who perceive it as arbitrary. There are major cultural and traditional practices that make the citizens more obsessed with local brew in the region.

vi. Lack of jobs and low levels of income contribute greatly to local brew production and sale. Alcohol production and sale is a major economic activity in Teso.

\section{RECOMMENDATIONS}

Ideally, the alcohol policy in Kenya needs a serious review. The following broad recommendations are made;

i. The producers of local brew who are arrested should be arraigned in a court of law where they should be charged adequately. Such arrests should not be done at night.

ii. Stringent and punitive measures should be devised to deal with the extravagant political interference in the implementation of alcohol policies in the region.

iii. Police manpower and financial resources should be increased at the stations near the Kenya-Uganda border. More police posts are required at least at every chief's post.

iv. Because it is easier to change a rule than changing a culture, legislation on local brew needs to be relaxed due to its elusiveness. Given that local brew is a potential brand for Kenya, there is a need for its standardization, legalization, regulation, promotion registration and inspection of registered joints.

v. All the producers of local brew need to be organized so that they can form a central club in an urban center that is licensed by the government so that all people with varied income levels can afford a drink.

vi. Attention should be shifted to the development of programs aimed at entrepreneurial education and agri-business skills apart from empowering local brewers economically.

vii. Involvement of all stakeholders. Policies should be crafted in a way that does not incriminate citizens, but rather, it should respond to the realities on the ground. The chronic local brewers in the area need to be involved in dialogues and surveys for them to have their opinions considered in the policy direction.

viii. At the same time, the government needs to form a department in the interior ministry that is dedicated to the regulation of local brew given the elusiveness of the matter and personnel insufficiency. 


\section{REFERENCES}

Andanje, H. (2011). Kenyans going to Uganda for a drink. Daily Nation. Accessed from http://www.nation.co.ke/news/Kenyans-going-to-Uganda-for-a-drink-/1056-109265612bh79az/index.html

Abelson, J., \& Gauvin, F. P. (2006). Assessing the impacts of public participation: Concepts, evidence and policy implications. Ottawa: Canadian Policy Research Networks.

Barrett, S. (2004). Implementation Studies: Time for a Revival? Personal Reflections on 20 Years of Implementation Studies. Public Administration, 249-262.

Bressers, H., \& O'Toole, L. (2005). Instrument selection and implementation in a networked context. In H. Eliadis, \& Howlett, Designing government: From instruments to governance. Montreal: McGill-Queens University Press.

Bryson, J. M., Quick, K. S., Slotterback, C. S., \& Crosby, B. C. (2013). Designing public participation processes. Public administration review, 73(1), 23-34.

Birkland, T. A. (2014). An introduction to the policy process: Theories, concepts and models of public policy making. Routledge.

Clausen, T., Rossow, I., Naidoo, N., \& Kowal, P. (2009). Diverse alcohol drinking patterns in 20 African countries. Addiction, 104(7), 1147-1154.

Chesang, R. K. (2013). Drug abuse among the youth in Kenya. International Journal of Scientific Technology Research, 2(6).

Deborah, R. (2008). Addressing the challenges of policy implementation: Key elements distilled from DECD experience paper presented on improvement of quality of education in Mexico,pg 1-4.

Gathigah, M. (2015). Kenya Struggles with Rising Alcoholism. Inter-press Service News Agency. http://www.ipsnews.net/2015/03/kenya-struggles-with-rising-alcoholism/. Accessed 20th September, 2016

Gayle D. (2014). More than 60 people killed and many more blinded or ill after drinking homemade alcohol laced with methanol to make it stronger in Kenya. Daily Mail. Published May 7, 2014. Accessed November 16th, 2016.

Gathura, G. \& Fortunate, E. (2012). Kenyans drink more with alcohol laws. Daily Nation. http://www.nation.co.ke/news/Kenyans-drink-more-with-alcohol-laws/1056-1392322-

jc0392z/index.html. Accessed on 13th November, 2016.

GoK, (2010). The status of illicit brew in Kenya, Nairobi, GoK printers.

Hill, M., \& Hupe, P. (2014). Implementing Public Policy. London: SAGE Publications Ltd.

Ikelegbe, A. (2006) Public Policy Analysis: Concepts, Issues and Cases. Lagos: Imprint Services.

Kielstra, P. (2010). Enabling policy implementation in economic intelligence unit report .Pp. 3- 17.

Macharia, D. (2016). Chang'aa brewer attacks and injures assistant chief during raid on den in Laikipia. Accessed from http://www.nation.co.ke/counties/Laikipia/Changaa-brewer-attacks-chief-inLaikipia/1183290-3137394-1411t9y/index.html

Mwathane, I. (2013). New alcohol law has weaknesses. Accessed from http://www.businessdailyafrica.com/Opinion-and-Analysis/New-alcohol-law-has-

weaknesses/539548-1664472-item-1-t70kvsz/index.html. Accessed on 14th November, 2016

Mkwesha, B. (2014) Obstacles in Implementing Alcohol Law in Kenya. Alcohol Industry, Policy, Prevention, Recovery, Sustainable Development. Accessed from http://iogt.org/blog/2014/01/15/obstacles-inimplementing-alcohol-law-in-kenya/. Accessed on 7th November, 2016.

Mureithi, (2010). Alcohol use in Central Province of Kenya: A baseline survey on magnitude, causes and effects from the perspective of community members and individual users, Nairobi

Mutisya, D., \& Willis, J. (2009). Budget drinking: alcohol consumption in two Kenyan towns. Journal of Eastern African Studies, 3(1), 55-73.

Michels, A., \& De Graaf, L. (2010). Examining citizen participation: Local participatory policy making and democracy. Local Government Studies, 36(4), 477-491.

Masaba, B.B. (2017). Alcohol Abuse Practices Among Residents of Busia Town, in Kenya. American Journal of Health Research. Vol. 5, No. 1, pp. 11-18.

Mugo, G. (2016). Parastatal car involved in accident found with 400 liters of chang'aa. The Star, Kenya. Accessed from http://www.the-star.co.ke/news/2016/03/13/parastatal-car-involved-in-accident-foundwith-400-litres-of-changaa_c1312254

Muraya, J. (2017). Policeman killed, another injured during Voi chang'aa raid. Accessed from http://www.capitalfm.co.ke/news/2017/04/policeman-killed-another-injured-during-voi- changaa-raid/ 
Miranda, E. M. (2007). Gang injunctions and community participation. University of Southern California.

Masinde, J. W. (2014). Effects of illicit brew drinking and intervention measures on unemployed youth in Bungoma County, Kenya (Doctoral dissertation, University of Nairobi).

NACADA. (2012). Report on rapid situation assessment of drug and substance abuse in Kenya. Nairobi: Government Printer.

Nelson, T. F., Toomey, T. L., Lenk, K. M., Erickson, D. J., \& Winters, K. C. (2010). Implementation of NIAAA. Alcohol Clinical Experimental Research, 1687-1693.

News24.com. (March, 2015). Alcohol remains popular treatment for illnesses in Kenya. Web. http://m.news24.com/kenya/National/News/Alcohol-remains-popular-treatmentfor-illnesses-in-Kenya20150320. Accessed November 16, 2016.

Odejide, O. A., \& Ibadan, N. (2006). Alcohol policies in Africa. African Journal of Drug and Alcohol Studies, 5(1), 27-39.

Otieno, J. K. (2015). Implementation of Alcohol and Drug Abuse Policy in Learning Institutions: The Case of Public Universities in Kenya (Doctoral dissertation).

Onyango, P. (2017). Administration Police camp torched by irate public. Kenya News Agency. Accessed from http://kenyanewsagency.go.ke/en/administration-police-camp-torched-by- irate-public/

Pulzl, H., \& Oliver, T. (2007). Implementing Public Policy. In F. Fischer, G. Miller, \& M. Sidney, Handbook of Public Policy Analysis, Theory, Politics and Methods (pp. 89-107). Florida: Taylor \& Francis Group, LLC.

Spratt, K. (2009). Policy implementation barrier analysis: Conceptual framework and pilot test in three countries in the US. Agency for international development (USAID), TASK order 1:1-36.

Teaka, J. (2015). "Dying for a Drink: How the Consumption of Home brew Affects Health within the Kibera Slum of Nairobi, Kenya". Independent Study Project (ISP) Collection. Paper 2026. Accessed from http://digitalcollections.sit.edu/isp_collection/2026

The Republic of Kenya. (2013). The Alcoholic Drinks Control (Amendment) Bill, 2013. Kenya Gazette. Received on January 10, 2014. Accessed on November 12, 2016.

Willis, J. (2006). Drinking crisis: Change and continuity in cultures of drinking in sub-Saharan Africa. African Journal of Drug and Alcohol Studies, 5(1), 2-15.

Weaver, R. (2010). Issues in governance studies: Implementation analysis to improve government performance. Available at www.brookings.edu/governance/issue-in-governance studies.aspx Retrieved on 15th November, 2016. 